\title{
First record of the genus Paragigagnathus Amitai and Grinberg, 1971 (Mesostigmata: Phytoseiidae) from Saudi Arabia with description of a new species
}

\author{
Fahad J. Alatawi, M. Kamran and J. Basahih
}

Acarology Laboratory, Department of Plant Protection, College of Food \& Agricultural Sciences, King Saud University, Riyadh, Saudi Arabia

\begin{abstract}
The genus Paragigagnathus Amitai and Grinberg (Acari: Phytoseiidae) is reported for the first time from Saudi Arabia. Paragigagnathus desertorum (Amitai and Swirski) and P. insuetus (Livshitz and Kuznetsov) were collected from Acacia sp. (Fabaceae) and Tamarix sp. (Tamaricaceae), respectively. Paragigagnathus madinaensis $\mathrm{n}$. $\mathrm{sp}$. is described and illustrated. The new species was found on Tamarix sp. in association with Obdulia daadi Al-Gboory (Prostigmata: Tenuipalpidae) from Al-Riyadh and Al-Madina regions of Saudi Arabia.
\end{abstract}

\section{ARTICLE HISTORY}

Received 15 May 2014

Accepted 4 August 2015

Online 17 September 2015

\section{KEYWORDS}

Phytoseiid mites; desertorum; insuetus; Al-Riyadh; Al-Madina

\section{Introduction}

The genus Paragigagnathus Amitai and Grinberg, 1971 (Acari: Phytoseiidae) comprises eight valid species (Chant and McMurtry 2007; Hajizadeh et al. 2010). Moraes et al. (2004) listed 10 species in this genus. But, Paragigagnathus tawfiki (Yousef, 1974) is a synonym of $P$. tamaricis Amitai and Grinberg (Hajizadeh et al. 2010), while P. amantis (Chaudhri et al., 1979) is declared as uncertain species because of inadequate description and illustrations (Chant and McMurtry 2007). The species of this genus are known from Egypt, Namibia, Madagascar, South Africa (Africa), Greece, Ukraine (Southeast Europe), Iran, Israel, Jordon, Pakistan, Russia, Turkmenistan, Tadjiskistan, Yemen (Middle East, Central and South Asia) (Amitai and Grinberg 1971; Livshitz and Kuznetsov 1972; Wainstein 1973; Yousef 1974; Amitai and Swirski 1978; Chaudhri et al. 1979; Ueckermann and Loots 1988; Kolodochka 1989; Papadoulis and Emmanouel 1991; Kuznetsov 1994; Ueckermann 1996; Moraes et al. 2004; Hajizadeh et al. 2010). Most of the species have been reported from Tamarix sp. (Tamaricaceae), suggesting that the species of this genus are confined in arid to semi-arid regions.

The genus Paragigagnathus was first placed in the subfamily Gigagnathinae Wainstein. Kolodochka (1994) transferred it to subfamily Amblyseiinae and tribe Amblyseiini Muma on the basis of dorsal setal pattern. After that, it was placed in the tribe Neoseiulini Chant and McMurtry because of cheliceral morphology, dorsal setal pattern and shape of female ventrianal shield (Chant and McMurtry 2003). Chant and 
McMurtry (2007) divided the genus Paragigagnathus in two species groups, desertorum and strunkovae, based on the position of sternal shield setae $\mathrm{ST}_{3}$ (on or off the sternal shield). However, in some species this character is not distinctive (Chant and McMurtry 2007; Hajizadeh et al. 2010). A key to the eight valid species of this genus was created by Hajizadeh et al. (2010). They separated the species based on the following morphological characters: length and shape of dorsal setae, most of dorsal setae either with or without tubercles, sternal setae $S T_{4}$ on the soft cuticle or on metasternal shields and number of teeth on moveable digit.

Phytoseiid mites are poorly investigated in Saudi Arabia, and to date only 19 species are known (Dabbour and Abdel-Aziz 1982; Fouly and Al-Rehiayani 2011; Al-Atawi 2011a, 2011b; Negm et al. 2012a, 2012b). This paper presents the first record of the genus Paragigagnathus from Saudi Arabia, with description of a new species $P$. madinaensis $\mathrm{n}$. sp. and two new records, $P$. desertorum (Amitai and Swirski) and P. insuetus (Livshitz and Kuznetsov).

\section{Materials and methods}

Three regions of Saudi Arabia, Al-Riyadh, Al-Madina and Al-Baha, were surveyed for the collection of Phytosiid mites during the years 2012-2014. Two collection methods were used: (1) different plant parts were shaken over a white paper and the mites were transferred using a camel hair brush into 70\% alcohol; (2) Tullgren funnels were used to extract mites from plant materials. The collected mite specimens were cleared in Nesbitt's fluid for 10-12 h. Subsequently, the specimens were mounted on slides in Hoyer's medium, and dried in oven at $40^{\circ} \mathrm{C}$ for 1 week. The mounted specimens were examined under a phasecontrast microscope (DM2500, Leica ${ }^{\circledR}$, Germany). Template illustrations were either drawn with pencil by using a drawing tube (Olympus ${ }^{\circledR}$, Japan) attached to the microscope, or different body parts of mites were pictured with an Auto-montage Software System (SYNCROSCOPY ${ }^{\circ}$, Cambridge, UK) attached to the microscope. Final processing of drawings was done in Adobe Illustrator (Adobe Systems Incorporated, USA). The terminology used in this study follows that of Chant and McMurtry $(2003,2007)$. All measurements are given in micrometers. Holotype and eight paratypes of new species are deposited at the King Saud University Museum of Arthropods (KSMA) and Acarology Laboratory, Department of Plant Protection, College of Food and Agriculture Sciences, King Saud University. One paratype (P1-accession no. Acy: 15/04) is deposited at the Agriculture Research Council, Plant Protection Research Institute, Pretoria, South Africa (ARC-PPRI).

\section{Results and discussion}

\section{Paragigagnathus Amitai and Grinberg}

Paragigagnathus Amitai and Grinberg 1971: 327; Karg 1983: 300; Kolodochka 1994: 3; Chant and McMurtry 2003: 39; Chant and McMurtry 2007: 31-32; Hajizadeh et al. 2010: 222-226.

Afrogigagnathus Yousef 1974: 381; Chant and McMurtry 2003: 39.

Ansaria Chaudhri, Akbar and Rasool 1979: 63; Chant and McMurtry 2003: 39.

Amblyseius (Pamiroseius) Karg 1983: 13. 
Amblyseius (Amblyseius) Ueckermann and Loots 1988: 118.

Pamiroseius Wainstein 1973: 954; Kolodochka 1989: 221; Chant and McMurtry 2003: 39. Phytocerus Amitai and Swirski 1978: 124; Chant and McMurtry 2003: 39.

Phytodromus Muma, Denmark 1993: 107.

\section{Paragigagnathus madinaensis $\mathbf{n}$. sp.}

(Figures 1, 2)

Female (Figures 1, 2). $n=16$, the measurements of holotype followed by those of 15 paratypes (female) in parenthesis.

Dorsal Idiosoma (Figure 1): Dorsal shield 339 (337-324) long and 196 (185-210) wide, elongate, slightly concave near seta $S_{2}$, strongly sclerotized, ornamented and with rugose lines/ patches; with 19 pairs of setae including setae $r_{3}$ and $R_{1}$ and 11 pairs of pores. Dorsal setae vary in length, only posteriorly set on prominent tubercles. Dorsal shield setal length: $j_{1} 17$ (16-18), $j_{3} 27$ (25-29), $j_{4}=j_{5} 26$ (22-30), $j_{6} 32$ (31-32), $J_{2} 34$ (32-38), J 20 (18-25), $z_{2} 34$ (32-36), $z_{4} 35$ (34-37), $z_{5} 25$ (21-29), $z_{1} 41$ (39-46), $z_{4} 43$ (40-46), $Z_{5} 38(35-41), s_{4} 37$ (35-38), $S_{2} 46(41-50), S_{4} 48(41-50), S_{5} 44$ (39-48) and lateral setae $r_{3} 18$ (15-21), $R_{1} 19$ (16-22). Peritreme extending up to setae $j_{1}$.

Ventral idiosoma (Figure 2A): Sternal shield smooth, convex anteriorly, slightly concave posteriorly, 70 (67-75) long, 52 (50-56) wide at the level of setae $S T_{2} ;$ with two pairs of setae and one pair of pores. $S T_{3}$ and $S T_{4}$ present on soft cuticle. $S T_{1}=S T_{2}$ 15(14-16), $S T_{3}=S T_{4}=14$ (13-15). Genital shield truncate posteriorly, 69 wide, wider than ventrianal shield, with one pair of setae. One pair of pores present lateral to genital shield on soft cuticle. Ventrianal shield and genital shield 7 apart, with a membranous fold in between. Ventrianal shield sole shaped, with marked waist, 28 wide at preanals, 57 wide (at anal setae), 106 long. L/W ratio at narrowest point 3.78, with three pairs of preanal setae, three circumanal setae and one pair of pores. Four pairs of setae, six pairs of pores and two pairs of metapodal platelets present on the membrane surrounding the ventrianal shield. $Z V_{1}=Z V_{3}=13, \mathrm{JV}_{4} 13(13-14), \mathrm{JV}_{5} 22$ (22-24), primary metapodal platelet 50 (47-52), secondary 18 (17-19).

\section{Spermatheca}

Vesicle is saccular, calyx thick, dish shaped, with annulated neck, atrium not adjacent to the calyx, major duct thick and long, minor duct not visible (Figure 2C).

\section{Chelicerae}

Fixed digit with three small apical teeth and a pilis dentilis; movable digit with one subapical blunt tooth (Figure 2D).

\section{Leg IV}

One macroseta on basitarsus 27 (26-27) (Figure 2B).

\section{Etymology}

The specific epithet 'madinaensis' refers to the city name 'Madina' where some paratypes of the new species were collected. 


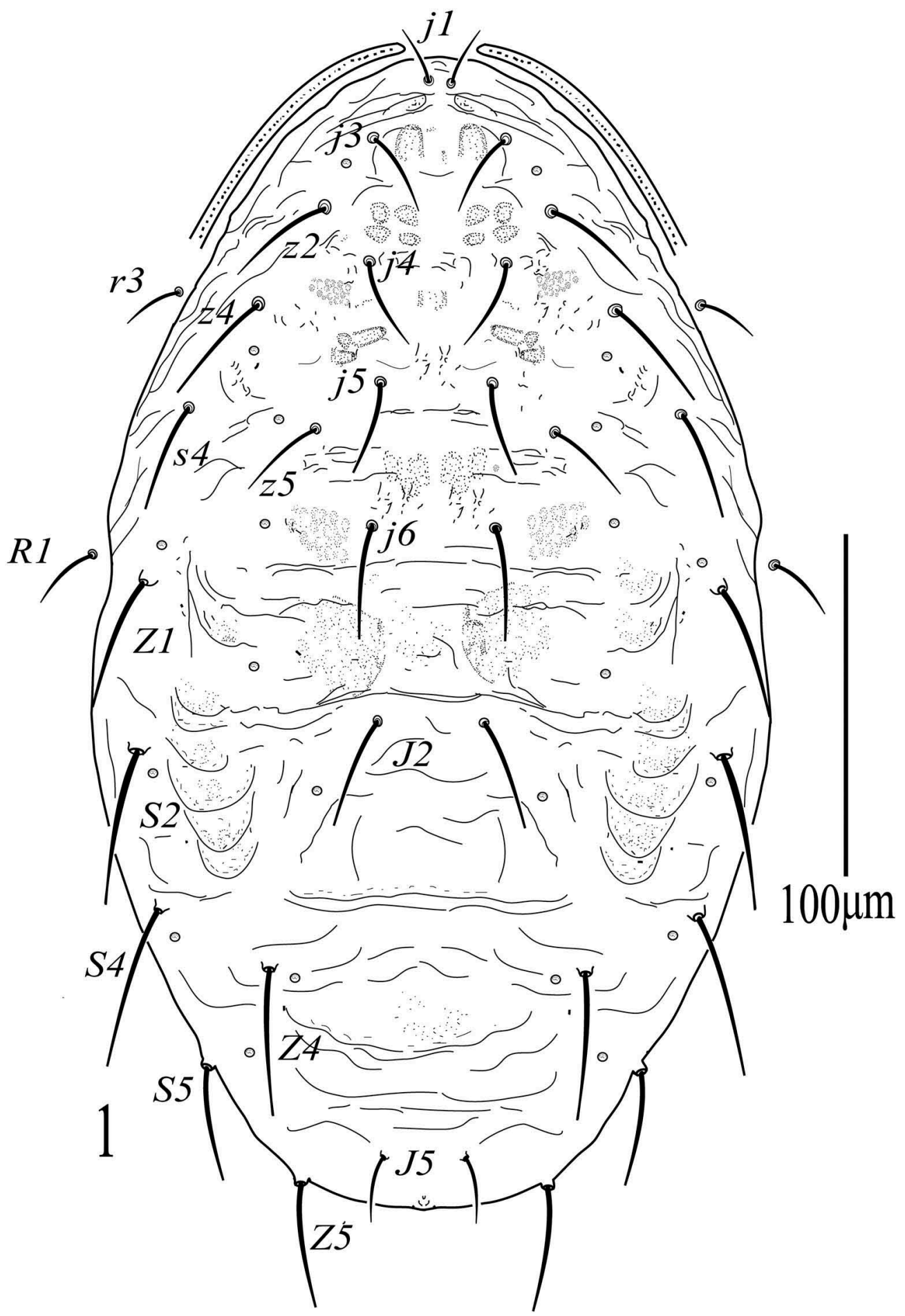

Figure 1. Paragigagnathus madinaensis n. sp. Female, Dorsal Shield. 


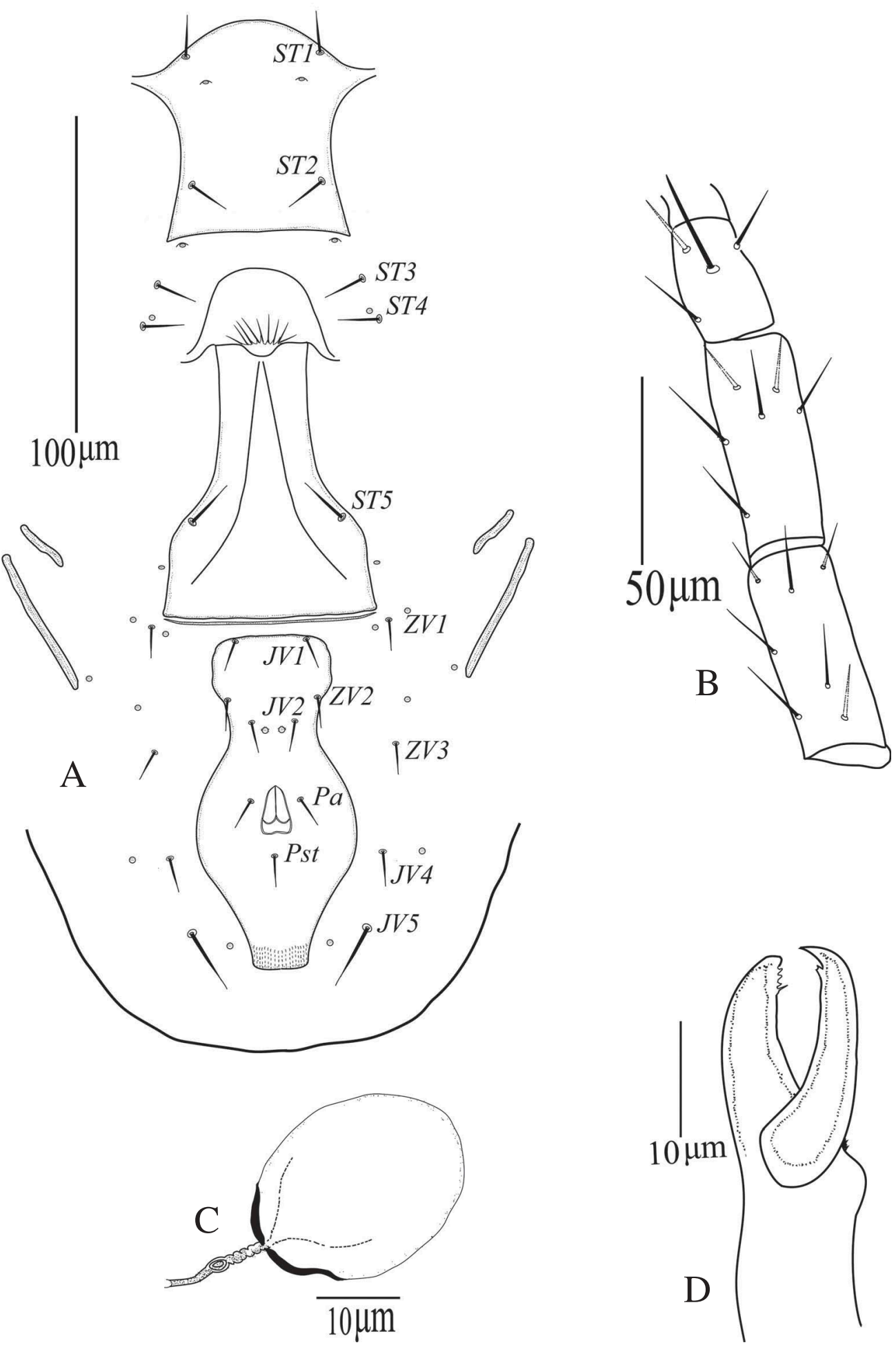

Figure 2. Paragigagnathus madinaensis n. sp. Female, (A) Idiosoma venter; (B) Spermatheca, (C) Chelicera; (D) Genu, tibia and basitarsus of Leg IV. 


\section{Type material}

Holotype and 10 paratype females, on aerial part of Tamarix sp. (Tamaricaceae), near Arqa over bridge, Wadi-e-Hanifa, Al-Riyadh, Saudi Arabia, 24. 4135N, 46.3704ㅌ, 18, Oct., 2012; five paratype females, Tamarix sp., 'Uhad' mountain, Al-Madina, Saudi Arabia, $24.3008^{\circ} \mathrm{N}, 39.364^{\circ} \mathrm{E}, 23$ Feb., 2013; all collected by M. Kamran.

\section{Remarks}

Paragigagnathus madinaensis n. sp. closely resembles Paragigagnathus namibiaensis (Ueckermann and Loots, 1988) because both share the following characters: sternal setae $S T_{4}$ on soft cuticle, movable digit with one tooth, ventrianal shield with three pairs of preanal setae, dorsal setae smooth and only posterior setae set on prominent tubercles. The new species can be distinguished from $P$. namibiaensis by much longer dorsal setae (15-48), sternal shield without posterolateral lobes, a dish shaped calyx of spermatheca, instead of comparatively short dorsal setae (13-35), sternal shield with posterolateral lobes and funnel shaped spermatheca in later species. The new species differs from $P$. strunkovae (Wainstein, 1973) by dish-shaped calyx of spermatheca and 3 pairs of preanal setae, while calyx of spermatheca is funnel shaped and preanal setae 2 pairs in later species.

\section{Paragigagnathus desertorum (Amitai and Swirski)}

Phytocerus desertorum Amitai and Swirski 1978: 123-127; Swirski and Amitai 1985: 185; 1997: 31.

Amblyseius desertorum Ueckermann 1996: 28.

Paragigagnathus desertorum (Amitai and Swirski), Chant and McMurtry 2003: 39-44;

Moraes et al. 2004: 159; Chant and McMurtry 2007: 33; Hajizadeh et al. 2010: 22-227. Female. $(n=8)$, the measurements of Saudi Arabian specimens in range.

\section{Dorsal idiosoma}

Dorsal shield 288-302 long and 204-212 wide at the level of setae $R_{1}$, strongly sclerotized, ornamented and with wax plates, rugose lines/ patches; with 19 pairs of setae including setae $r_{3}$ and $R_{1}$. All dorsal setae thick and set on prominent tubercles. Dorsal shield setal length: $j_{1} 16-18, j_{3} 26-31, j_{4} 24-27, j_{5} 29-30, j_{6} 32-35, J_{2} 38-40, J_{5} 13-14, z_{2}$ $35-37, z_{4} 36-38, z_{5} 24-26, Z_{1} 36-39, Z_{4} 46-49, Z_{5} 45-47, s_{4} 39-42, S_{2} 45-47, S_{4} 45-48, S_{5}$ 46-49 and lateral setae $r_{3} 23-24, R_{1} 18-19$. Peritreme extending up to setae $j_{1}$.

\section{Ventral idiosoma}

Sternal shield smooth, convex anteriorly and posteriorly, 76-79 long, 57-59 wide at the level of setae $S T_{2}$; with two pairs of setae and one pair of pores. $S T_{3}$ present on metasternal platelets, $S T_{4}$ present on soft cuticle. Genital shield truncate posteriorly, 55-58 wide, wider than ventrianal shield, with one pair of setae. One pair of pores present lateral to genital shield on soft cuticle. Ventrianal and genital shields with a membranous fold in between. Ventrianal shield smooth, elongate, sole shaped, with marked waist, 36-37 wide at preanals, 60-61 wide (at anal setae), 99-105 long. L/W ratio at narrowest point 3.43, with three pairs of preanal setae, three circumanal setae and one pair of pores. Four pairs of setae, six pairs of pores and two pairs of metapodal platelets present on the membrane 
surrounding the ventrianal shield. $Z V_{1}=Z V_{3}=11-12, J V_{4}$ 14-15, $J V_{5}$ 17-18, primary metapodal platelet 36-39, secondary 16-18.

\section{Spermatheca}

Vesicle is saccular, calyx, dish shaped, not very thick, atrium not adjacent to the calyx, major duct long, thick, minor duct not prominent.

\section{Chelicerae}

Fixed digit with one bifid tooth and a pilis dentilis; the movable digit smooth.

\section{Leg IV}

One macroseta on basitarsus 23-25.

\section{Material examined}

Eight females, 130 km Al-Madinah road, Makkah, Acacia raddiana L. (Fabaceae), 7 Feb., 2014, coll. M. Kamran.

\section{Distribution and hosts}

Israel, ex. Acacia raddiana L. (Fabaceae), association with Thrips sp. (Thripidae) (Amitai and Swirski 1978; Swirski and Amitai 1985, 1997); Yemen ex unidentified plants (Ueckermann 1996). It was found on Acacia raddiana in association with Sonotetranychus sp. (Acari: Tetranychidae) in Saudi Arabia.

\section{Paragigagnathus insuetus (Livshitz and Kuznetsov)}

Amblyseius insuetus Livshitz and Kuznetsov 1972: 27.

Pamoroseius insuetus Kolodochka 1989: 227.

Paragigagnathus insuetus (Livshitz and Kuznetsov), Kolodochka 1994: 3; Chant and McMurtry 2007: 31-33.

Female. $(n=3)$, the measurements of Saudi Arabian specimens in range.

\section{Dorsal idiosoma}

Dorsal shield 338-345 long and 228-235 wide at the level of setae $R_{1}$, strongly sclerotized, ornamented with rugose lines/ patches; with 19 pairs of setae including setae $r_{3}$ and $R_{1}$. All dorsal setae thick, only posterior setae set on prominent tubercles. Dorsal shield setal length: $j_{1} 14-15, j_{3} 15-16, j_{4} 14-15, j_{5} 14, j_{6} 16-17, J_{2} 16-17, J_{5} 10-11, z_{2}$ $16-17, z_{4} 17-18, z_{5} 14-15, Z_{1} 16-18, Z_{4} 17-19, Z_{5} 25-27, s_{4} 16-18, S_{2} 18-19, S_{4} 22-23, S_{5}$ 25-26 and lateral setae $r_{3} 16-17, R_{1} 14-15$. Peritreme extending up to setae $j_{1}$.

\section{Ventral idiosoma}

Sternal shield smooth, 76-78 long, 65-67 wide at the level of setae $S T_{2}$; with two pairs of setae and one pair of pores. $S T_{3}$ present on soft cuticle, $S T_{4}$ present on metasternal platelets. Genital shield truncate posteriorly, wider than ventrianal shield, with one pair of setae. One pair of pores present lateral to genital shield on soft cuticle. Ventrianal shield smooth, elongate, sole shaped, with marked waist, 45-48 wide at preanals, 65-67 wide (at anal setae), 106-109 long. L/W ratio at narrowest point 2.78 , with three pairs of 
preanal setae, three circumanal setae and one pair of pores. Four pairs of setae, six pairs of pores and two pairs of metapodal platelets present on the membrane surrounding the ventrianal shield. $Z V_{1}=Z V_{3}=10-11, J V_{4} 12, J V_{5}$ 17-18, primary metapodal platelet 45-46, secondary 15-16.

\section{Spermatheca}

Vesicle is saccular, calyx, dish shaped, thick, atrium not adjacent to the calyx, major duct long, thick, minor duct not prominent.

\section{Chelicerae}

Fixed digit with one tooth and a pilis dentilis; the movable digit with tooth.

\section{Leg IV}

One macroseta on basitarsus 20-21.

\section{Material examined}

Three females, Tamarix sp. (Tamaricaceae), Wadi-e-Turba, Al-baha, Saudi Arabia, 19.4957 N, 041.4734ㅌ, alt. 1798 m, 24 Feb., 2013, coll. M. Kamran.

\section{Distribution and hosts}

Ukraine, Crimea ex (Livshitz and Kuznetsov 1972); Greece and Turkmanestan (Kolodochka 1989; Papadoulis and Emmanouel 1991); Iran (Hajizadeh et al. 2010); ex Tamarix sp., Thuja occidentalis L. (Cuspressaceae); Populus sp. (Saliaceae).

\section{Acknowledgements}

The authors wish to thank the Deanship of Scientific Research, College of Food and Agriculture Research Center, at King Saud University, Riyadh for providing facilities and funds to complete this research.

\section{Disclosure statement}

No potential conflict of interest was reported by the authors.

\section{References}

Al-Atawi FJ. 2011a. Phytophagous and predaceous mites associated with vegetable crops from Riyadh, Saudi Arabia. S J Biol Sci. 18:239-246.

Al-Atawi FJ. 2011b. Six new records of predaceous mites associated with trees from Riyadh, Saudi Arabia. Acarines. 5:37-39.

Amitai S, Grinberg T. 1971. Description of a new phytoseiid genus and species (Acarina: Mesostigmata) from Israel. Israel J Entomol. 6:327-335.

Amitai S, Swirski E. 1978. A new genus and new records of phytoseiid mites (Mesostigmata: Phytoseiidae) from Israel. Israel J Entomol. 12:123-143.

Chant DA, McMurtry JA. 2003. A review of the subfamily Amblyseiinae Muma (Acari: Phytoseiidae): Part I. Neoseiulini new tribe. Internat J Acarol. 29:3-46. 
Chant DA, McMurtry JA. 2007. Illustrated keys and diagnoses for the genera and subgenera of the Phytoseiidae of the world (Acari: Mesostigmata). West Bloomfield, MI: Indira Publishing House; pp 220.

Chaudhri WM, Akbar S, Rasool A. 1979. Studies on the predatory leaf inhabiting mites of Pakistan. Faisalabad, Pakistan: University of Agriculture; pp 243. Tech Bull No.

Dabbour Al, Abdel-Aziz Ml. 1982. Scientific note on Acarina in Saudi Arabia. J College Agric King Saud University. 4:113-116.

Denmark HA. 1993. Revision of the genus Phytodromus Muma (Acari: Phytoseiidae). Internat J Acarol. 19:107-121.

Fouly H, Al-Rehiayani SM. 2011. Predaceous mites in Al-Qassim Region, Saudi Arabia, with description of two new laelapid species (Acari: Gamasida: Laelapidae). J. Entomol. 8:139-151.

Hajizadeh J, Faraji F, Rafatifardf M, Kamranfard F. 2010. The genus Paragigagnathus Amitai and Grinberg (Acari: Phytoseiidae) in Iran, with a key to the known species. Syst Appl Acarol. 15:222-227.

Karg W. 1983. Systematische untersuchung der Gattungen und Untergattungen der Raubmilbenfamilie Phytoseiidae Berlese, 1916, mit der beschreibung von 8 neuen Arten. Mitt Zool Mus Berlin. 59:293-328.

Kolodochka LA. 1989. A revision of the phytoseiid mites of the genus Pamiroseius Wain. (Parasitiformes: Phytoseiidae). Entomol Obozr. 68:221-229 (in Russia).

Kolodochka LA. 1994. A revision of the genus Paragigagnathus (Parasitiformes, Phytoseiidae). Part 1. History and a new concept of the genus (In Russian, English summary). J Ukrain Entomol. 2:3-8.

Kuznetsov NN. 1994. Two new phytoseid mite species (Parasitiformes, Phytoseiidae) from Armenia and Tadjikistan. Vestn Zool. 2:78-81 (in Russia).

Livshitz IZ, Kuznetsov NN. 1972. Phytoseiid mites from Crimea (Parasitiformes: Phytoseiidae) (in Russian). In: Pests and diseases of fruit and ornamental plants. Proceedings of The All-Union V. I. Lenin Academy of Agricultural Science, The State Nikita Botanical Gardens, Yalta, Ukraine. 61:13-64.

Moraes GJ, McMurtry JA, Denmark HA, Campos CB. 2004. A revised catalog of the mite family Phytoseiidae. Zootaxa. 434:1-494.

Negm MW, Alatawi FJ, Aldryhim YN. 2012a. A new species of Neoseiulus Hughes, with records of seven species of predatory mites associated with date palm in Saudi Arabia (Acari: Phytoseiidae). Zootaxa. 3356:57-64.

Negm MW, Alatawi FJ, Aldryhim YN. 2012b. Incidence of predatory phytoseiid mites in Saudi Arabia: new records and a key to the Saudi Arabian species (Acari: Mesostigmata: Gamasina: Phytoseiidae). Syst Appl Acarol. 17:261-268.

Papadoulis GT, Emmanouel NG. 1991. The genus Amblyseius (Acari: Phytoseiidae) in Greece, with the description of a new species. Entomol Hellenica. 9:35-62.

Swirski E, Amitai S. 1985. Notes on phytoseiid mites (Mesostigmata: Phytoseiidae) from the Dead Sea region of Israel. Israel J Entomol. 19:181-192.

Swirski E, Amitai S. 1997. Annotated list of phytoseiid mites (Mesostigmata: Phytoseiidae) in Israel. Israel J Entomol. 31:21-46.

Ueckermann EA. 1996. Some Phytoseiidae of Yemen (Acari: Mesostigmata). Fauna of Saudi Arabia. 15:20-36.

Ueckermann EA, Loots GC. 1988. The African species of the subgenera Anthoseius De Leon and Amblyseius Berlese (Acari: Phytoseiidae). Entomol Mem dept Agric Water Supply Rep S Africa. 73:1-168.

Wainstein BA. 1973. New genus and species of Phytoseiidae (Parasitiformes). Zool Zhurnal. 52:953955 (in Russia).

Yousef ATA. 1974. A new genus of the family Phytoseiidae (Acarina: Parasitoidea). Bull Soc Entomol Egypt. 58:381-383. 